\title{
The Development Process of Education and Training Institutions in China
}

\begin{abstract}
Tianrui Xiao
University of Sydney

*Corresponding author. Email: 1571599425@qq.com

ABSTRACT

Now that everyone is qualified to take the college entrance examination (Gaokao), the competition among students is more intense. Because getting into a good university is conducive to students' future development, more and more students and parents pay attention to students' learning, and the demand for taking part in tutoring outside school has also increased. The research theme of this paper is the development process of off-campus tutoring institutions in China. Through the research methods of distributing questionnaires to students and parents and class observation, the problems existing in current educational institutions will be found. The learning stage and reasons for students or parents to sign up for educational institutions; the factors that students and parents will pay attention to when they choose educational institutions; students' performance in class, such as being absent-minded in class, chatting with other students and other situations and the reasons of their actions. Through the above content to help education institutions to understand consumers' ideas, improve institutional problems attract more customers, and the teacher can also through understanding the students' performance, and their idea to change teaching methods, make the teaching more efficient, at the same time, students can improve their learning efficiency, good for all three parties.
\end{abstract}

Keywords:_China, Off-campus tutoring, Tutoring institution.

\section{INTRODUCTION}

Since the Compulsory Education Law of the People's Republic of China was enacted in April 1986, more and more children can receive education, which means that students will become more and more competitive [1]. To make their children have better academic performance, more and more parents will arrange for their children to take extra lessons, and this leads to the off-campus tutoring agencies gradually developing.

However, off-campus tutoring requires time, effort, and money, which may lead to improve academic performance of affluent children, while poor children are not able to attend tutoring, which may reduce their chances of changing their lives, and this is an educational injustice. In addition, China promulgated the "Opinions on further reducing the homework burden of students in compulsory education and the burden of off-campus training", referred to as the "double reduction policy", the content of the policy is to ease the burden of excessive homework and off-campus tutoring for students undergoing compulsory education [2]. There are detailed regulations on off-campus training institutions.
Therefore, the research topic of this paper is the development process of off-campus tutoring institutions in China. The research methods of this study are questionnaire and observation. The significance of this study is to understand students' and teachers' views on these institutions through qualitative research methods, and to help improve teachers' teaching methods by combining different views and policies.

\section{LITERATURE REVIEW}

By reading Explorations in Teaching Research by a Tutoring Institution in China, how an educational institution develops in the industry and how to provide guaranteed service quality for students' personalized needs can be known [3]. The study began with documentary analysis of the institution's history and interviews with people who had worked at the institution since its inception.

Data show that in the early days, case institutions' syllabuses and materials were entirely resolved by their tutors. This leads to differences in progress between classes. This, coupled with differences in tutor teaching styles, complicates student schedules. As the institution 
grew in size, the user experience inevitably suffers. In order to meet the market demand for qualified tutors and a unified teaching process, the institution has designed a specific mode of operation to ensure the quality of teaching during the standardization process. Standardized textbooks greatly reduce the burden of setting teaching goals and organizing teaching content for teachers. Tutors can focus more on teaching by preparing more interesting class activities and getting a better grasp of what is to be taught.

As new branches are set up across the country, standardized textbooks need to be revised due to differences in regional exams, teaching systems and textbooks. In order to solve this problem, headquarters and its branch departments are divided, with headquarters responsible for establishing basic courses, while its branch offices focus on meeting the needs of the local tutoring market. An intelligent classroom system for classroom instruction was also established and later upgraded to an intelligent teaching system, by which tutors could use visual images and videos to show experimental processes that might not be easy to express verbally. At the same time, the use of electronic courseware can significantly reduce the burden of teachers and improve their teaching efficiency.

Currently, case institution designs more digital teaching materials and apply them in the classroom. In addition, the division of teaching research responsibilities is becoming more precise. In terms of teaching materials, they must be reviewed several times before being finalized by the teaching research team. Mentors also go through several rounds of practice and evaluation. The teaching and research team continuously improves the materials based on feedback from frontline tutors and students.

In order to survive in China's highly competitive tutoring market, the case institution needs to improve the user experience of its service and promote its visibility. It requires stricter control of teaching quality across the country, with many tutoring agencies trying to attract students by publicizing their better-known tutors and stabilizing the teaching skills of the tutor team to ensure that each tutor has a satisfactory level of teaching. It believes that good teachers can only be produced if a solid foundation is established. This shows that the quality of lecturers and the reputation of institutions are very important for tutoring institutions. Efforts have also been made to standardize teaching materials, upgrade paper textbooks to digital ones and use more digital teaching methods. This shows that educational institutions consider training methods to be very important to the institutions themselves, which are important factors to attract more students or parents.

\section{RESEARCH METHODS}

The research methods used in this study are questionnaires and observation.

The questionnaire is sent to students participating in off-campus tutoring and parents sending their children to participate in off-campus tutoring in the form of an online electronic questionnaire. The questionnaire is anonymous and both students and parents fill in it voluntarily. There are 11 questions in the questionnaire, including the current learning stage of the participants who fill in the questionnaire, the learning stage and form of off-campus tutoring, the average money spent on off-campus tutoring every semester and the time spent on off-campus tutoring every week, the problems that need to be improved in the current educational institutions, people's search for what the tutoring institutions value and the reasons for participating in tutoring can be known via collecting the questions from the participants.

The observation is based on my internship in an afterschool tutoring institution as a teaching assistant in 2021 and the after-school tutoring experience I once participated in.

The above methods were adopted because the data can be analyzed from two different perspectives of students and teachers, making the research more comprehensive.

\section{PARTICIPANTS}

The selection of participants in filling in the questionnaire is random. The questionnaire is published on the Internet and people fill in it voluntarily. A total of 55 people participated in filling in the questionnaire, including students in grades 1-3 of primary school, junior middle school students, senior high school students and college students who have participated in off-campus tutoring.

For classroom observation, the observation objects were the teachers teaching in $\mathrm{X}$ institution and the remedial students in $\mathrm{X}$ Institution. The students are in grade one, grade two, grade three, grade five and grade six separately, the subjects that they study are Chinese, math and English. Teachers are both male and female, who give lessons to the students in $\mathrm{X}$ institution.

\section{RESULTS}

\subsection{Data from questionnaires}

A total of 55 people participated in filling in the questionnaire, and there were 49 students and 6 parents. The students are in grades 1 to 3,7 to 9,10 to 12 from primary school to university. Among them, college students accounted for the highest proportion, a total of 31 , accounting for $56.36 \%$ of the total number of students; 
This was followed by 10 students in Grade 10 to 11 , accounting for $18.18 \%$ of the total number. There are 6 students in Grade 7 and Grade 8, accounting for 10.91\%; There are 4 students in Grade 9, accounting for $7.27 \%$; There are 2 students in Grade 12 and 2 students in Grade 1 to 3 , accounting for $3.64 \%$ of the total.

Most students choose to enroll in education and training institutions when they are in middle school and high school. According to the questionnaire (multiple choice question), 36 students have signed up for tutoring institutions in junior middle school, accounting for $65.45 \%$; 35 students signed up for tutoring institutions in high school, accounting for $63.64 \% ; 27$ students, accounting for $49.09 \%$, signed up for tutoring institutions in primary school. 3 students, accounting for $5.45 \%$, have signed up for tutoring institutions in preschool. This shows that there are students signing up for tutoring at every level of learning, even in kindergarten, but middle and high school students are still the majority of participants in off-campus tutoring. This may be because Chinese students in grade 9 and 12 have the High school entrance exam and the Gaokao, which are both important exams that determine which high school and university students go to.

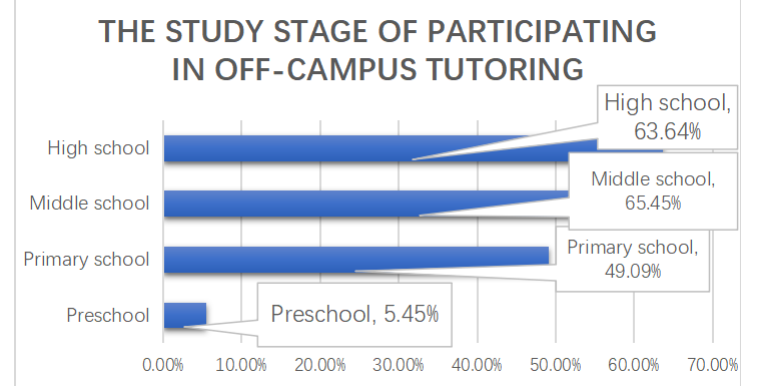

Figure 1 The study stage of participating in off-campus tutoring

As for the form of training, one-on-one is the most popular. 27 students, accounting for $49.09 \%$, took one-toone tutoring. Secondly, the proportio 任 $\mathrm{n}$ of small class teaching is the same as that of large class teaching. This may be because one-on-one tutoring is more targeted, which is convenient for teachers to take care of students' progress and can improve students' learning efficiency.

THE FORM OF TRAINING

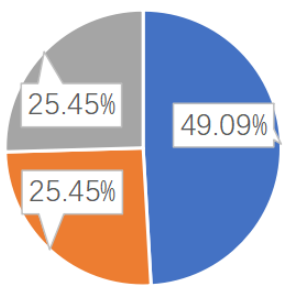

- One-on-one - Small classes - Large classes

Figure 2 The form of training
Most of the money spent on education and training per semester of students is more than $500 \mathrm{RMB}$. Only 2 students chose the option less than or equal to $500 \mathrm{RMB}$, accounting for $3.64 \%$; 16 students chose the option of 1,500 to $4,000 \mathrm{RMB}$, accounting for the highest proportion of $29.09 \%$. According to the household income and Consumption Expenditure in the first quarter of 2021 [4], the per capita disposable income of Chinese residents was 9,730 yuan in the first quarter. That means parents are willing to spend at least $15 \%$ of their income, and possibly more, on after-school education. The amount of money that parents spend on their children's tutoring may also mean that tutoring institutions are not cheap.

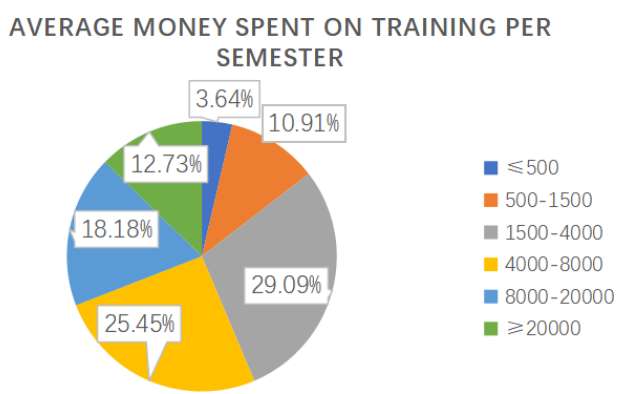

Figure 3 Average money spent on training per semester

As for the survey of satisfaction, most students or parents are satisfied with the effect of educational institutions. Among them, 25 students are satisfied with the effect of attending the current educational institution, accounting for the highest proportion $(45.45 \%)$ ). At the same time, 8 students, accounting for $14.55 \%$, think it is useless to attend off-campus tutoring. This illustrates some problems that may exist in tutoring institutions, if the tutoring institution can improve the problem, it can help students' academic performance improve, parents can reduce the burden, and it can also make the tutoring institution attract more students, which is beneficial to both sides.

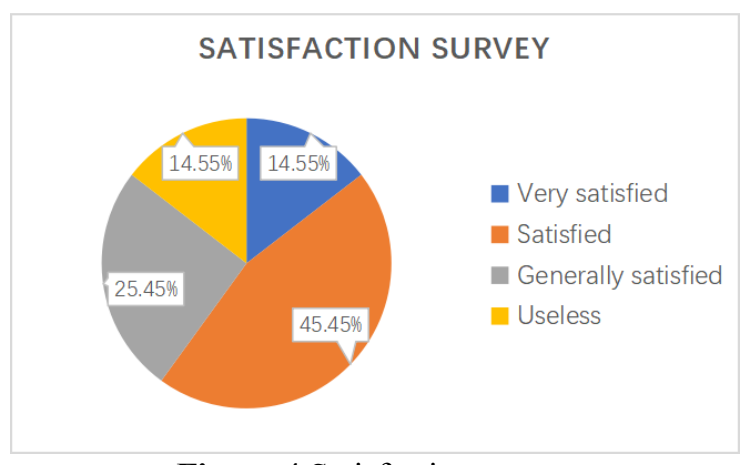

Figure 4 Satisfaction survey

As for the survey of the amount of time spent each week on training outside the school. 34 students spent about 2 to 5 hours per week in education and training institutions, accounting for the highest proportion $(61.82 \%)$. It is roughly $1-3$ lessons, which means that the 
efficiency of students' learning and the teaching method of the lecturer are very important during the children's tutoring period. There are 9 students who spend 5 to 10 hours and less than 2 hours in education and training institutions each week, accounting for $16.36 \%$. The remaining three students spend more than 10 hours in education and training institutions every week, accounting for $5.45 \%$.

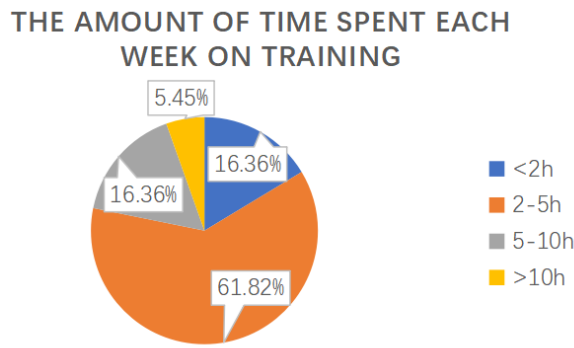

Figure 5 The amount of time spent each week on training

As for the survey of students and parents on what needs to be improved in their current educational institution (multiple choice question). 31 students think the price of training and the quality of lecturers need to be improved, accounting for the highest proportion $(56.36 \%)$.

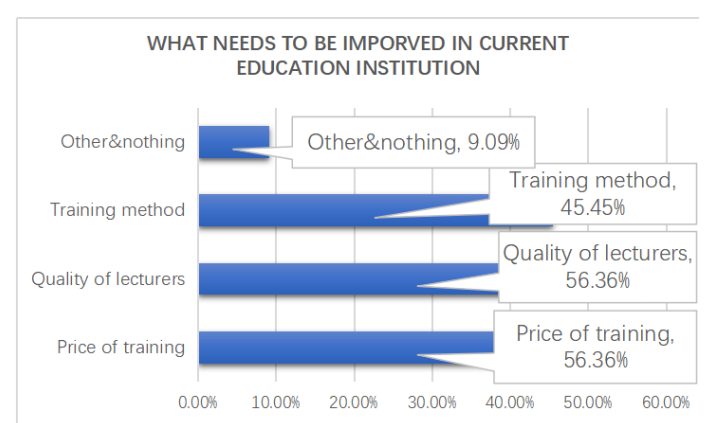

Figure 6 What needs to be improved in current education institution

A multiple-choice survey of what students or parents will focus on when they attend to a training institution. 51 people pay more attention to the quality of lecturers, accounting for the highest proportion (92.73\%); 29 people will pay more attention to training methods, accounting for the second, $52.73 \%$.

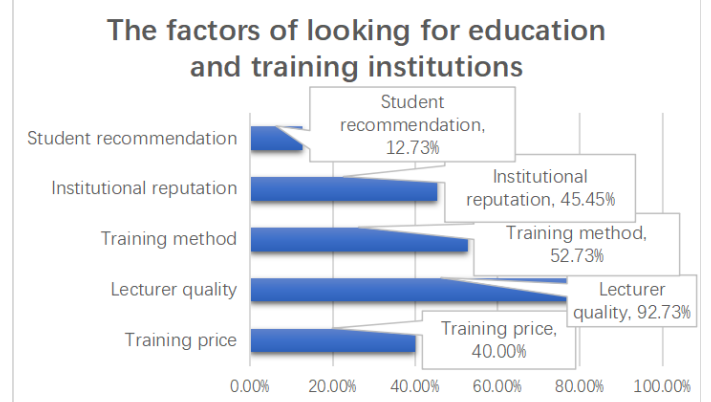

Figure7 The factor of looking for education and training institutions
Investigation on the reasons for participating in education and training institutions. Poor academic performance accounted for the majority, a total of 27 students, accounting for the highest proportion, $49.09 \%$; Two people chose to find something to do and follow the trend respectively, accounting for the smallest proportion $(3.64 \%)$. Almost half of the students choose to attend tutoring because of poor academic performance, which may be because teachers in school cannot take care of every student in the class, which further shows that the quality of the lecturer is very important for students, and may also be a reason for students to choose one-to-one tutoring.

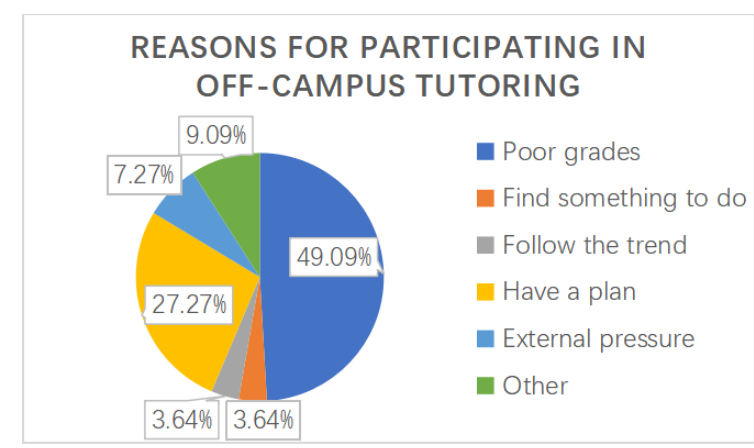

Figure 8 Reasons for participating in off-campus tutoring

The last question is about the double reduction policy. Under the background of the implementation of the double reduction policy, 17 students decided whether they would choose another teaching method according to the situation; Five would not have taken

another route. This shows that the double reduction policy does affect students' tutoring. If the training mode is changed (one to one tutoring), it may increase the expenses of parents. If students choose not to attend remediation, their academic performance may fluctuate.

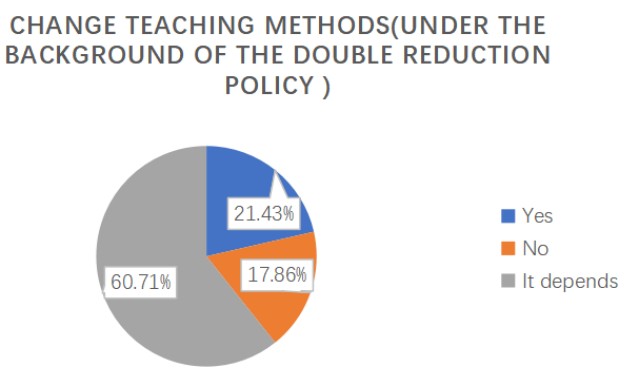

Figure 9 Change teaching methods (under the background of the double reduction policy)

\subsection{Analysis based on the classroom observation}

In terms of classroom observation, the class has two teaching forms, one is online teaching and the other is offline teaching. The average class size is about 20 students, and each class lasts two hours (including breaks). In the offline English class of grade one, students 
actively participate in the teacher's interaction, but some students will sleep in class and be distracted. In the beginning, the teacher reminded the students, but if the students did not change, the teacher did not remind them again. In the offline English class of grade 2, the students were all very active, but sometimes they would be distracted. After the teacher reminded them several times, the students would listen carefully. In the offline math class of the third grade, most of the students listened carefully and completed the exercises well, but some students liked to chat together or did not listen to the teacher, and the teacher would choose to ignore the students even after the teacher reminded them. In the online Chinese class of grade 3, the students listened carefully and spoke actively, but occasionally they would be distracted or disconnected, and the teacher would correct them with a little reminder. In the offline English class of grade 5 , students were very active in speaking, but sometimes the classroom was too noisy. After the teacher reminded them to be quiet for a period of time, but the noise would resume later.

Through classroom observation, there are the following findings. First, in almost every class, there will be students who do not concentrate on the class. The younger the students are, the more difficult it is to concentrate on the class content for a long time, and the teacher cannot remind them every time, because they have to take care of the situation of most people. This situation also appears in the article Misbehaviors in Turkish and English classrooms [5]. In the interview about the 'problem students' in the misbehaviors in Turkish and English classrooms, teachers said that children are unhappy and the main reason for their misbehaviors may be related to their families.

The author also summarizes the reasons for the misbehaviors of students in the article. First of all, the difficulty of subject content is very important, such as mathematics and science. If students don't understand an activity, they are easily distracted by irrelevant things. Second, whether the students are interested in the activity. This is related to whether the students understand the significance of the teacher's doing this activity. If they do not understand this, misbehaviors may occur, especially in practical activities. Third, teachers' tolerance. If teachers are less strict, students are more likely to commit misconduct. Of course, the frequency and type of misconduct also depend on various factors, such as students' age, gender, time of day, different parts of the course, the seating arrangement in the classroom, type and theme of learning activities.

In this regard, teachers can also take corresponding measures to try to improve students' bad behavior. In the Classroom discipline and student responsibility: the students' view [6], students said that most of the time, when their teachers deal with discipline in class, they will interrupt their study. But, for more responsible students in the classroom, teachers participate more in their decision-making and provide more non instruction tips, identify good behavior, and discuss with misbehaving students to make them understand the impact of their behaviors on others and think about how to perform better. When teachers encounter bad behavior of students in the classroom, they should calmly punish misconduct and reward good behavior. In addition, they can also let students participate in the decision-making of some rules and consequences of the class.

\section{CONCLUSION}

Overall, through the questionnaire, this paper learned the basic situation of students' participation in afterschool tutoring, as well as their suggestions to the classroom and their attention to signing up for afterschool tutoring; Teachers understand students' performance in class and their ideas through classroom observation. The results of the questionnaire show that parents or students think that both the price of training and the quality of lecturers need to be improved, and these two are also the important factors they will refer to when choosing educational institutions. Classroom observation results show that most students are absentminded although the teacher reminds students several times, so students own self-control is very important, and teachers can also enrich their teaching content, such as more games to increase interaction with students and criticize students who violate classroom discipline, encourage students with excellent performance, or formulate class rules and regulations with students. In addition, students in the pursuit of good grades are a worth encourage behavior, but too much take a fancy to their test scores is not correct, teachers should give correct guidance; Finally, students' willingness to study independently is very important, which will greatly determine their learning outcomes and learning efficiency. So, parents should ask their children what they think, and teachers should pay more attention to students' psychology.

This essay also has some deficiencies. First, during my internship as a teaching assistant, Double reduction policy has not been officially issued, so the class content and class time have no large difference, but after the policy issued, the class time will be reduced to 90 minutes, this may lead to the class content and teaching methods of teachers to change. Secondly, the research methods of this paper are relatively single, so more research methods can be used to help get the conclusion. Future research will also focus on the changes of tutoring institutions under the background of the double reduction policy, which may increase the workload of teachers, because the shortening of class time means that teachers need to simplify class content or give more emphasis to help students learn. 


\section{REFERENCES}

[1] Compulsory Education Law of the People's Republic of China,

http://www.npc.gov.cn/wxzl/gongbao/201507/03/content_1942840.htm

[2] Opinions on Further Reducing the Burden of Homework and Off-campus Training for Students in Compulsory Education, http://www.moe.gov.cn/jyb_xwfb/gzdt_gzdt/s5987/ 202107/t20210724_546566.html

[3] Bai, Y., Tang, X., Li, X., \& Fan, S. (2019). Explorations in Teaching Research by a Tutoring Institution in China. ECNU Review of Education, 2(1), 87-94. https://doi.org/10.1177/2096531119840866

[4]Household income and consumption expenditure in the first quarter of 2021, http://www.gov.cn/xinwen/2021-04/16/content_ 5599995.htm

[5] Türnüklü, A., \& Galton, M. (2001). Students' misbehaviours in Turkish and English primary classrooms. Educational Studies, 27(3), 291-305. https://d1wqtxts 1 xzle7.cloudfront.net/47803095/St udents_Misbehaviours_in_Turkish_and_E2016080 4-18088-11vfc3-with-cover-pagev2.pdf? Expires $=1635183991 \&$ Signature $=\mathrm{Zq} 7 \mathrm{wZa}$ LIi9dX4IcV6DXnV1UWt6TvEa0BKjqea4ImCsXu e2Kug4n0k141HbFOaxFg2cDMjUSD9Cx1LjTiZ6hVBJouKeP2M8N-QKdDejh65E2VqeCJCSTY5GJdgGpKGavA39w0ghTXjQ v0 L1pnYWms9IukZHCwsrWoGIu2km0jWqlfmq7j3 GMAU1nEOa5XzHdprokPQXOq45-

11zfN8R0aopsXomnvHhRLZaRvLUXZXYOYcW A2JM14MMdmpFYIZmh-gNa6y1QJyAQ0j37kEvxV90Ha8wqJjs6qEow1rWhI8bg4 GpHStqOSLNjUXtOQvOniLEeh7insOJtUb1muO A__\& Key-Pair-Id=APKAJLOHF5GGSLRBV4ZA

[6]Lewis, R. (2001). Classroom discipline and student responsibility: The students' view. Teaching and teacher education, 17(3), 307-319. https://citeseerx.ist.psu.edu/viewdoc/download?doi $=10.1 \cdot 1.1040 .6425 \&$ rep=rep $1 \&$ type $=$ pdf 